\title{
Sensor-less Brushed DC Motor Speed Control with Intelligent Controllers
}

\author{
AMIR SALMANINEJAD, RENE V. MAYORGA \\ Faculty of Engineering and Applied Science \\ University of Regina \\ 3737 Wascana Parkway, Regina, Saskatchewan, S4S 0A2
}

CANADA

\begin{abstract}
A Direct Current (DC) Motor is usually supposed to be operated at a desired speed even if the load on the shaft is exposed to changes. One of its applications is in automatic door controllers like elevator automatic door drivers. Initially, to achieve this aim, a closed loop control can be applied. The speed feedback is usually prepared by a sensor (encoder or tachometer) coupled to the motor shaft. Most of these sensors do not always perform well, especially in elevator systems, where high levels of noise, physical tensions of the mobile car, and maintenance technicians walking on the car, make this environment too noisy. This Paper presents a new approach for precise closed loop control of the DC motor speed without a feedback sensor, while the output load is variable. The speed here is estimated by the Back EMF (BEMF) voltage obtained from the armature current. First, it is shown that a PID controller cannot control this process alone, and then intelligent controllers, Fuzzy Logic Controller (FLC) and Adaptive Neuro Fuzzy Inference Systems (ANFIS), assisting PID are applied to control this process. Finally, these controllers' performance subjected to a variable mechanical load on the motor shaft are compared.
\end{abstract}

Keywords: Adaptive Neuro Fuzzy Inference Systems, Fuzzy Logic Controller, Sensor-less, Speed Control. Received: February 3, 2021. Revised: June 12, 2021. Accepted: July 7, 2021. Published: July 12, 2021.

\section{Introduction}

With technological advances in power electronics, development of low-cost digital controllers, simple and linear mathematical models of a Brushed DC Motor (BDCM) that makes it easier to be controlled, these devices have been used more and more in different industries. To mention some other advantages, we can consider their low cost, high torque, simplicity and easy speed control. All these have made BDCMs more popular in Robotics, Factory automation, automatic door drivers and elevators, chemical and food industries and aeronautics [1 6].

BDCMs are an important part of automatic door systems. In old elevator systems, light doors with a symmetric load in open and close directions hired DC motors without speed sensors or accurate speed controllers. Open-loop controllers, based on Armature Voltage Control (AVC), used to have an acceptable performance. But, in modern designs with more safety requirements, heavy doors like steel covered and glass doors with powerful springs pulling doors closed led to asymmetric load which resulted in difficulties to control shaft speed without a feedback. Sensors are used and closed-loop controllers are applied in these systems. However, sensors are sensitive to noise and physical damage, need more space to be installed, and require more maintenance.
More importantly, the elevator system is a very noisy environment. To address sensors' problems and improve the system efficiency, new types of motors are designed (Brushless DC motors and PMSMs) to make sensor-less controllers applicable. These devices are also more efficient. However, these types of motors are more expensive, hardly replaceable, and need more settings. With all the advantages for modern motors, there is a big demand for BDCMs because of their simplicity.

Intelligent systems have been hired as controllers in a variety of applications. As a DC motor controller, A. A. Sadiq et al applied a Mamdani FLC in 2013 [1]. In 2009, Gerasimos G. Rigatos used an ANFIS as a motor controller [2]. Rasoul Rahmani et al used FLC to control DC motor speed in 2012 [8]. In 2017, Yasser Ali Almatheel and Ahmed Abdelrahman applied FLC Mamdani to control a DC motor speed [7]. A Speed control for BDCMs without sensor feedback is proposed in this project. With this new approach a BDCM can still work in a noisy environment under a changing load without any additional sensors. This important is possible with intelligent controllers (Fuzzy Logic Controller (FLC) or ANFIS) being applied. This Paper presents a new approach for precise closed loop control of the BDCMs speed without feedback sensors, while the 
output load is oscillating. Here, FLC and ANFIS assisting a PID are applied to control this process.

\section{System-Dynamics}

Fig. 1 shows the DC Motor model. The mathematical model is a combination of electrical and mechanical characteristics with related equations. In this model, the field is supposed to be provided by permanent magnets.

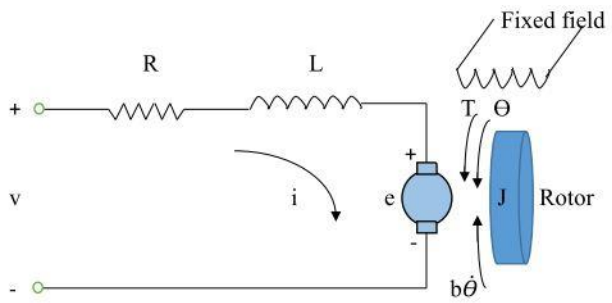

Fig 1. DC Motor model.

R: Armature resistance $(\Omega)$

L: Armature inductance $(\mathrm{H})$

J: Rotor inertia (kgm)

$\mathrm{b}$ : Viscous friction coefficient $(\mathrm{Nms} / \mathrm{rad})$

e: BEMF

$\theta$ : Rotor angle position

$\dot{\theta}:$ Rotor speed $(=\omega)$

$i$ : Rotor current

$\mathrm{v}$ : Rotor Input voltage

In this work, it is supposed that there is no speed feedback and speed is extracted from the BEMF, $e$ which is achieved by rotor current and voltage measurement.

In what follows, electrical and mechanical equations of DC motor are represented:

$$
e=k_{e} \omega=k_{e} \dot{\theta}
$$

Electrical Equations:

$$
-v+R i+L \frac{d i}{d t}+e=0
$$

For BEMF, equation (2) can be written as:

$$
e=v-R-L \frac{d i}{d t}
$$

Mechanical Equations:

$$
T=J \dot{\omega}+b \omega
$$

Electromechanical Equation:

$$
\begin{array}{r}
T=k_{T} i \\
\mathrm{~T}=T_{m}+T_{\text {load }}
\end{array}
$$

Laplacian domain for equation (2):

$$
\begin{aligned}
\operatorname{Err}(s)=R I(s) & +\operatorname{LsI}(s) \\
= & (R+L s) I(s)
\end{aligned}
$$

Where error is $v-e$ (fig 2).

$$
I(s) \div \operatorname{Err}(s)=\frac{1 / R}{1+\frac{L}{R} \cdot s}
$$

For equation (4) in Laplacian domain:

$$
J s \Omega(s)+b \Omega(s)=T(s)
$$

Where,

$$
\Omega(s)=\frac{1}{J s+b} \cdot T(s)
$$

And from there,

$$
\Omega(s) \div T(s)=\frac{1 / b}{1+J / b \cdot s}
$$

The shaft speed, while the shaft load is variable:

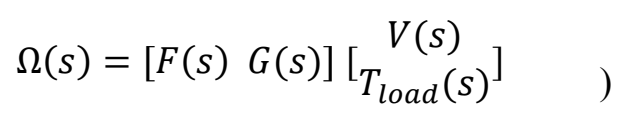

$$
\begin{aligned}
& F(s) \\
& \left.=\frac{K_{T}}{(b R)\left(1+\frac{L}{R} \cdot s\right)\left(1+\frac{J}{b} \cdot s\right)+K_{T} K_{e}}\right)
\end{aligned}
$$

While, ' $\mathrm{e}$ ' is the feedback to the control system. 


$$
\begin{aligned}
& G(s) \\
& \left.=\frac{R+L s}{(b R)\left(1+\frac{L}{R} \cdot s\right)\left(1+\frac{J}{b} \cdot s\right)+K_{T} K_{e}}\right)
\end{aligned}
$$

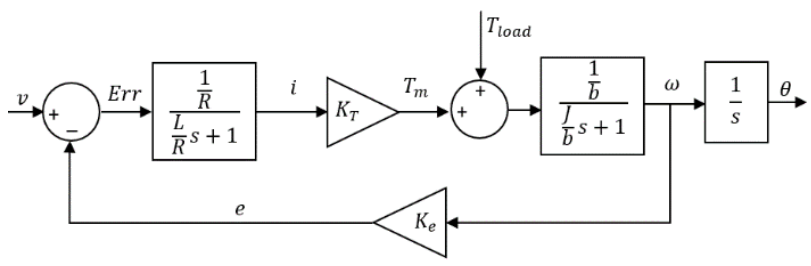

Fig 2. Plant block diagram.

\subsection{FLC and ANFIS Controllers}

To design a classical controller like P, PI, or PID, the mathematical model of the system should be known and analyzed. In this method, normally the plant model is simplified and linearized. If the system model is nonlinear, partially linearizing and making a tradeoff between accuracy and simplicity will be helpful. For some nonlinear and/or complicated plants, it is usually hard to model and inaccurate to simplify. On the other hand, intelligent controllers (FLC, Artificial Neural Networks (ANNs), ANFIS, etc.) not only are simpler in applying but also can handle nonlinear and more complicated models without any simplification [2]. More importantly, a mathematical model of the plant is not necessarily known [8].

In Fuzzy Inference Systems, the design is based on the experience and the information collected from the practical model. However, the mathematical model can be still unknown [4]. There are two well implemented fuzzy models known as Mamdani and Sugeno [7] which are also implemented in this project as controllers. Compared to ANNs controllers, FLCs are more popular, thanks to the rule-based and experience-based basis of their design. Enough experience of the plant behavior may lead to a model free controller design having no mathematical model [1]. ANNs are equipped with learning abilities that may cover the unknown aspects of a plant in controllers design.

Being able to learn and designed based on field experience (parameters selection), ANFIS has the positives of FLCs and ANNs. It can be considered as the best intelligent controller for many applications, especially in control systems. For ANFIS, the membership functions can be chosen carefully to satisfy the experimental knowledge about the system, and a learning process based on the input/output data pairs may compensate the shortage of this model in some areas. These two aspects of ANFIS have made it as the most popular controller among intelligent controllers. Furthermore, the ANFIS as a nonlinear controller deals with the nonlinearity of the plant in a control system [9].

The ANFIS used in this work as a controller has two inputs and one output, five layers and a regular feed-forward structure. Each layer has a mathematical function as follow [9]:

First layer, which is an adaptive layer:

$$
O_{1, i}=\mu A_{i}(x) \quad, \quad O_{1, i}=\mu B_{i}(y)
$$

Second layer, with fixed nodes:

$$
O_{2, i}=w_{i}=\mu A_{i}(x) \mu B_{i}(y)
$$

Third layer, with fixed nodes:

$$
O_{3, i}=\bar{w}_{i}=\frac{w_{i}}{w_{1}+w_{2}}, i=1,2
$$

Forth layer, which is another adaptive layer in this network:

$$
O_{4, i}=\overline{w_{i}} f_{i}=\overline{w_{i}}\left(p_{i} x+q_{i} y+r_{i}\right)
$$

And finally, for the single node output layer:

$$
O_{5,1}=\sum \overline{w_{i}} f_{i}=\frac{\sum_{i} w_{i} f_{i}}{\sum_{i} w_{i}}
$$

\section{Simulation and Results}

The work is simulated in MATLAB using Simulink Toolbox. A BDCM, a controlled voltage source, a controlled PWM, an H-bridge, a current sensor, a controlled rotational damper, and a rotational motion sensor blocks are used in this model. The PWM frequency is $4 \mathrm{kHz}$, the armature resistance is 1.5 $\mathrm{Ohm}$, the armature inductance is $12 \mathrm{e}-6 \mathrm{H}$, and the BEMF constant is $72 \mathrm{e}-6 \mathrm{~V} / \mathrm{rpm}$. To calculate the shaft speed based on equation (3), a voltage and current sensors measure the armature voltage and current. 
Multiplied by armature constants, the BEMF is calculated and an RMS module smoothen this output. A gain is applied to this output to prepare a speed feedback. The simulated plant is shown in fig 3 .

Initially, an PID controller is applied to the plant, with a constant load on the motor shaft and then the PID is tuned for the fastest response without overshoot. Fig 4 shows this setup block diagram.

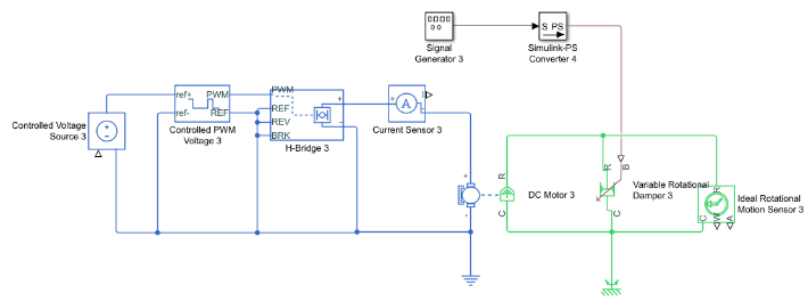

Fig 3. Simulation of BDCM plant in MATLAB.

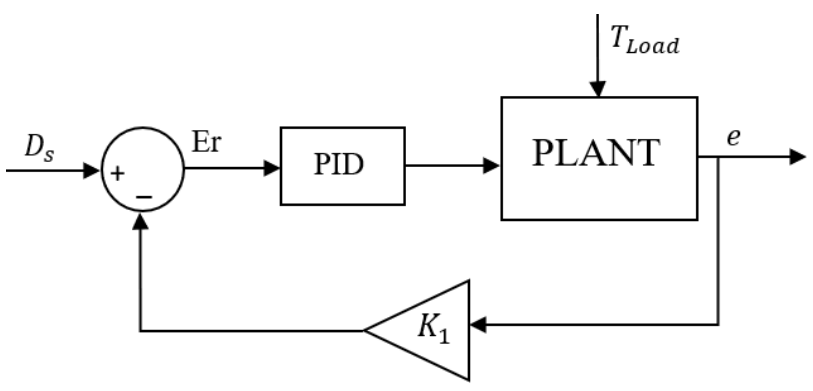

Fig 4. PID controller applied to the plant.

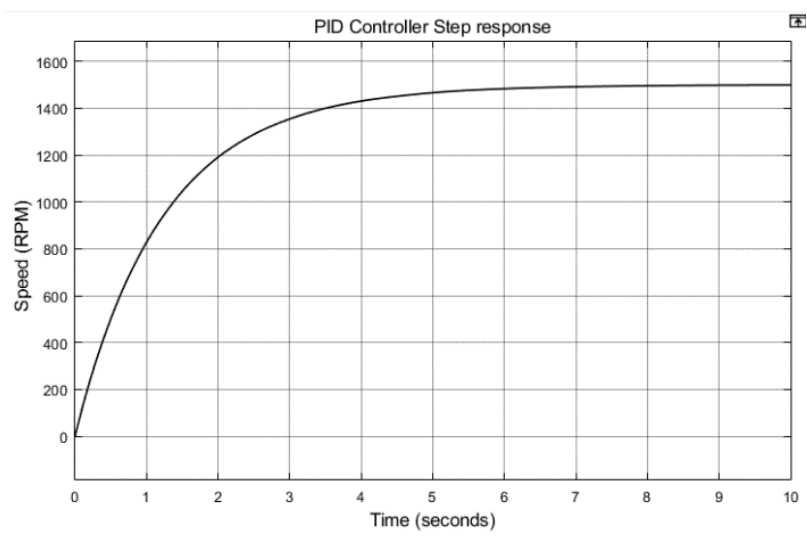

Fig 5. Step response for PID controller with constant load on the shaft.

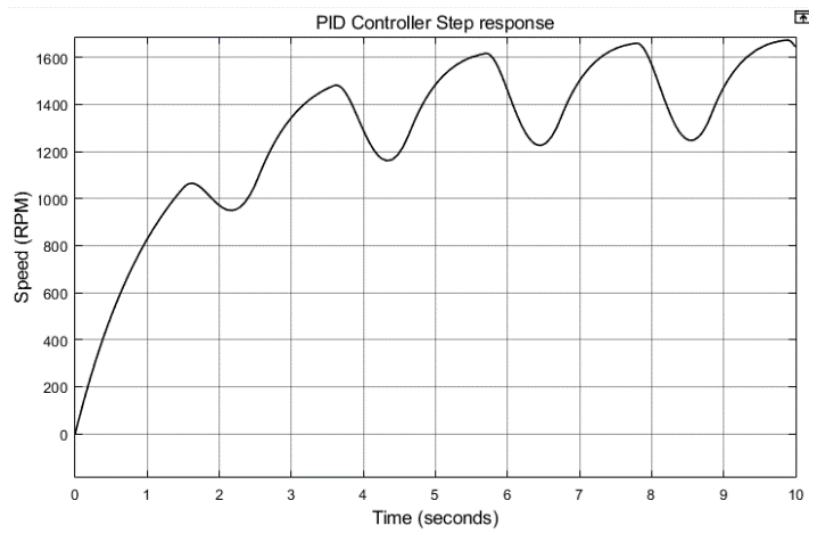

Fig 6. Step response for PID controller with oscillating load on the shaft.

$K_{1}$ is a constant depends on the motor parameters and the load values chosen in this plant (fig 3). Before providing the feedback to the input, an RMS module is applied to the calculated BEMF to provide a more stable speed feedback. The electrical variables, current and voltage, change very fast but the shaft speed is slow changing. The output of the RMS module changes gently. This RMS module is hidden in gain $K_{1}$, in fig 4. For a desire speed of 1500 and constant load on the shaft, this system (fig 4) is being tested and the step response of this setup system is shown in fig 5. With a changing load on the motor shaft the controller is not able to regulate the shaft speed. This is shown in fig 6. Then the PID controller has been assisted with an intelligent controller. See fig 7.

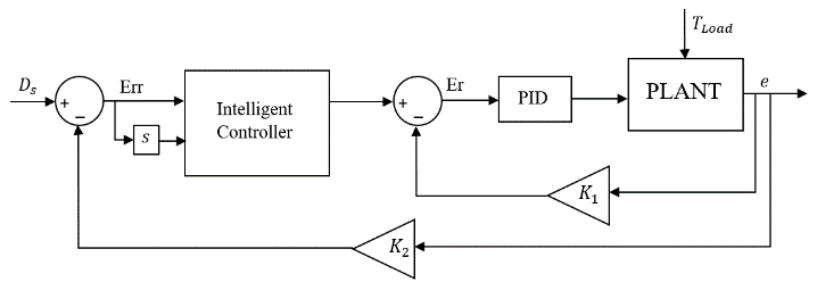

Fig 7. The plant is controlled with and intelligent controller along with the PID.

In fig 7, both controllers are in series and the feedback to both is the BEMF. The gain $K_{2}$ is the same as gain $K_{1}$ with a small constant value multiplied for adjustment. The input to the intelligent controller is the error $(E r r)$, the difference between desire speed $\left(D_{S}\right)$ and the feedback, and the changes in error, $d E r r$. The intelligent controller can be a Zero-Order Sugeno fuzzy controller, Mamdani fuzzy controller or an ANFIS. These controllers are applied to the plant according to fig 7 and the results are compared. The intelligent controller output is a value which is 
considered as the desire input to PID controller. The PID module output is a voltage which is an input to PWM generator module.



(a)

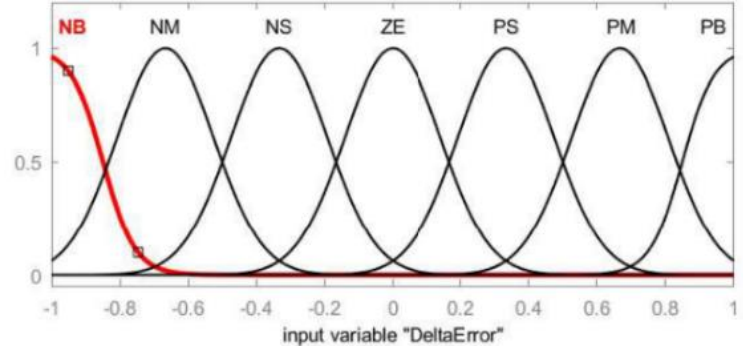

(b)

Fig 8. Input MFs for Mamdani FIS. Error MFS are shown in (a) while the rate of change in error values are shown in (b).

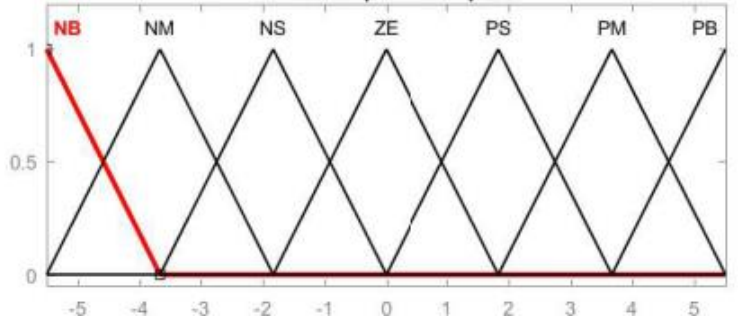

Fig 9. Output MFs for Mamdani FIS

\subsection{Mamdani FLC}

In this model a Mamdani FLC along with a PID controller are proposed to control the speed while the shaft load is variable. See fig 7. This FLC is designed based on two inputs and one output. The Membership Functions (MFs) for speed deviation and delta deviation are a combination of Sigmoidal Functions and Gaussian MFs. The output MFs are Triangular and Trapezoidal MFs. In the following figures, these MFs are presented.

In fig $8 a$ and $b$, the changes in inputs are being considered as Negative Big (NB), Positive Big (PB), Negative Medium (NM), Positive Medium (PM),
Negative Small (NS), Positive Small (PS), and Zero (ZE). This MFs are similarly named for the output of this FIS. However, the output MFs are triangular (fig 9).

Mamdani FLC is designed based on 49 rules. This is a combination of changes in error and delta error in FLC input. Fig 10 shows a diagram of these rules. To show how these rules work, a surface is drawn in three dimensions. These dimensions are error, changes in error and the output. Fig 11 shows the rules surface for Mamdani FLC.

\begin{tabular}{|c|c|c|c|c|c|c|c|c|}
\hline \multirow{2}{*}{\multicolumn{2}{|c|}{$\begin{array}{c}\text { Rules } \\
\text { Diagram }\end{array}$}} & \multicolumn{7}{|c|}{ DELTA DEVIATION } \\
\hline & & NB & NM & NS & ZE & PS & PM & PB \\
\hline $\mathrm{D}$ & NB & NB & NB & $\mathrm{NB}$ & NB & $\mathrm{NM}$ & NS & $\mathrm{ZE}$ \\
\hline$E$ & NM & NB & NB & NB & NM & NS & ZE & PS \\
\hline I & NS & NB & NB & NM & NS & $\mathrm{ZE}$ & PS & PM \\
\hline A & ZE & NB & $\mathrm{NM}$ & NS & $\mathrm{ZE}$ & PS & PM & PB \\
\hline 1 & PS & NM & NS & ZE & PS & PM & PB & PB \\
\hline 0 & PM & NS & ZE & PS & PM & PB & PB & PB \\
\hline $\mathrm{N}$ & PB & ZE & PS & PM & PB & PB & PB & PB \\
\hline
\end{tabular}

Fig 10. The FLC Mamdani rules diagram

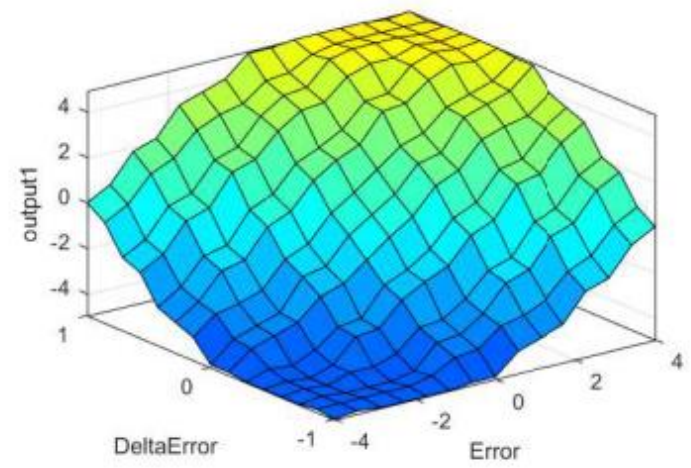

Fig 11. The Mamdani FLC Input-Output surface

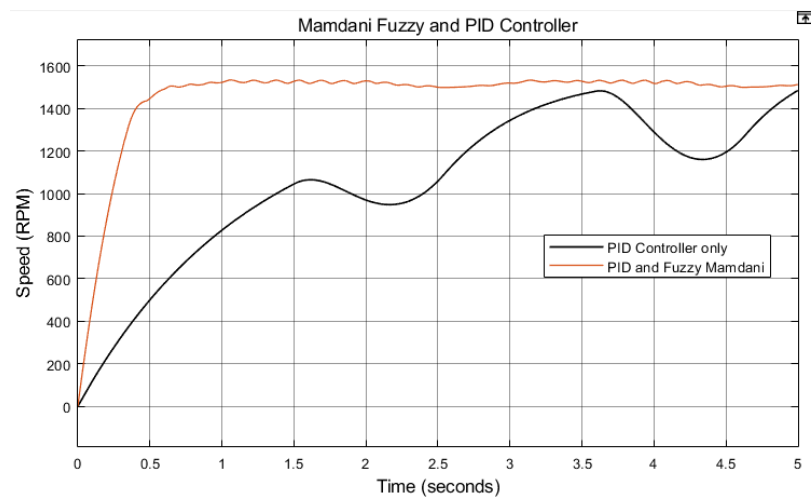

Fig 12. Mamdani FLC vs PID alone step response. 
This controller is applied to the plant to control the shaft speed without a physical speed feedback from the motor shaft. In this configuration, Mamdani FLC is the intelligent controller shown in fig 7. A variable load is applied to this system same as the one applied to PID alone in fig 6. The PID and FLC are tuned for the new settings. The step response of this system is shown in fig 12.

Fig 12 shows that the FLC helping the PID has compensated the system faster. The response is faster, since the current speed is more than 90 percent of the desired speed in 0.5 second. While for PID alone, this has happened after 3.5 seconds. Additionally, the changing load does not affect the output shaft speed very much. The shaft speed is oscillating around the desired speed smoothly. The desired speed is 1500 RPM. The load on the shaft oscillates with $3 \mathrm{~Hz}$ frequency. The damper on the motor shaft shown in fig 3 has a damping coefficient of $1 \mathrm{e}-8 \mathrm{~N}^{*} \mathrm{~m} /(\mathrm{rad} / \mathrm{s})$, and the amplitude of the sinusoidal applied to this variable damper is $1 \mathrm{e}-6$.

\subsection{Sugeno FLC}

Zero order Sugeno FLC is the second intelligent controller tested for this plant based on fig 7 configuration. This FLC is designed based on two inputs, one output. The MFs for speed deviation and delta deviation are a combination of Sigmoidal Functions and Gaussian MFs. The output MFs are Triangular and Trapezoidal MFs. Figs 8 to 10 show these $14 \mathrm{MFs}$ and the rules table for this FLC. The rules surface for this model is a 3D figure which shows the output values based on changes in error and change rate of error. This is shown in fig 13.

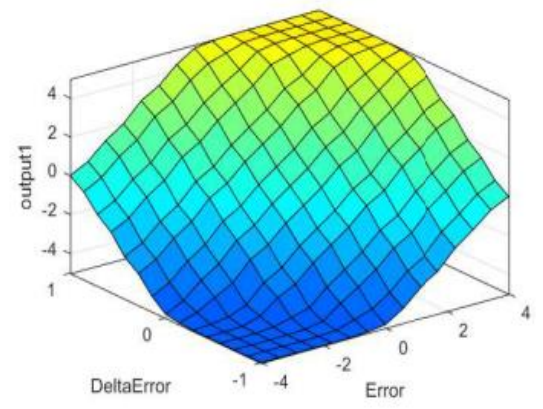

Fig 13. Zero-Order Sugeno FIS Controller surface.



Fig 14. Sugeno FLC vs PID alone step responses.

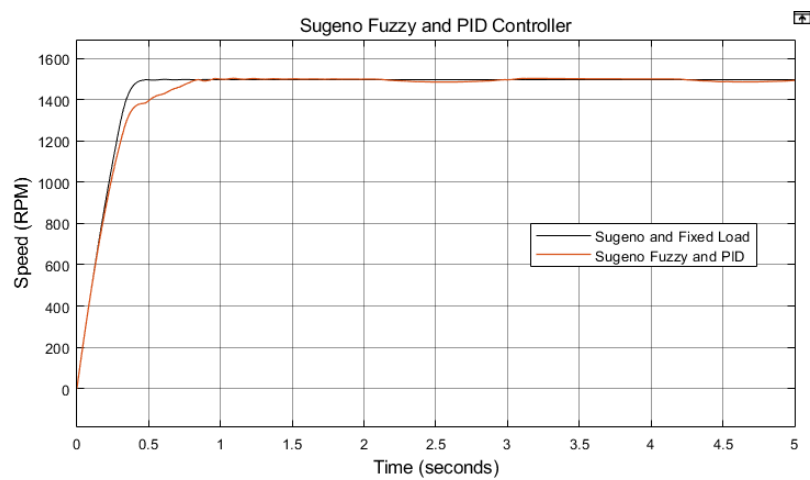

Fig 15. Sugeno FLC applied to a fixed load on the shaft vs variable load.

Fig 14 shows the step response of the system controlled with Sugeno FLC assisting the PID controller. To show how oscillatory is the shaft speed under the variable load, the step response for a variable load and a fixed load are compared in fig 15 . The shaft speed reaches the desire speed in a longer time when the load is variable, and after that the shaft speed follows the desire speed with a reasonable oscillation.

Comparing figs 5 and 15, PID is slow in step response. For PID the settling time is more than 5 seconds, while it takes less than 0.5 second for intelligent controller assisting system to settle. An elevator door course is usually less than 5 seconds. To decrease settling time with PID alone, we may experience an overshoot that is not desirable.

\subsection{ANFIS}

Finally, in this section, an ANFIS is applied to the plant to control this process. This controller has two inputs and one output, five layers and a regular feedforward structure. In this model, the ANFIS is assisting the PID to regulate the shaft speed based on the diagram shown in fig 7 . 
To collect some data from the system to train the ANFIS, a closed loop control system was setup with a shaft speed feedback. After having this setup, a variety of loads are applied to the model, and the input and output data is recorded in tables. The frequency and amplitude of the shaft load $\left(T_{\text {Load }}\right)$ changed during the data record. The input table recorded error and error change rates right after the first summation block in fig 16. And the output table records values out of the 'Sugeno FLC' block. 4000 datasets were collected in total to have enough training and test data for ANFIS. This training model is shown in fig16.

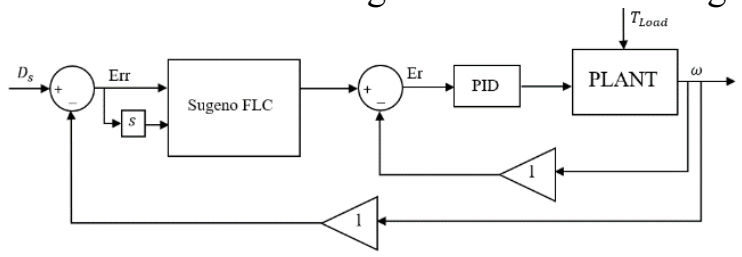

Fig 16. Model setup for training data collection.

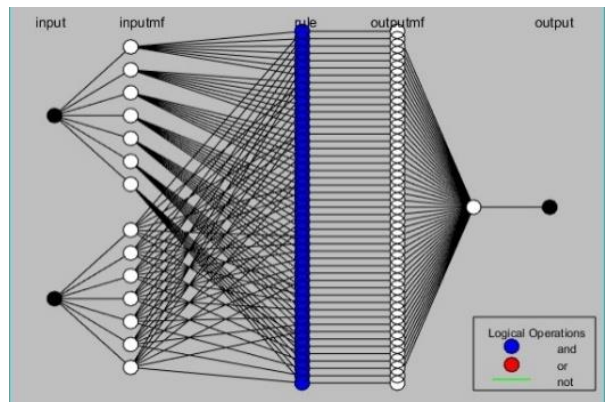

Fig 17. Two inputs one output ANFIS diagram.

An ANFIS was designed based on 49 rules, 7 Gaussian MFs for each input, and a Zero-Order Sugeno in its output. There are two inputs, one output, and the mathematical functions are represented in equations (15) to (19).

Fig 17 shows this diagram. To make the ANFIS a more dynamic controller, a variety of input/output data were collected as mentioned before.

This ANFIS was trained based on the simulation data. The total error was about 0.5 in the 300th epoch of training process. There is no tuning required for ANFIS as a controller.

The trained ANFIS is substituted in intelligent controller position in fig 7 and the step response of the system with a variable load on the shaft is shown in fig 18. The load oscillates with a frequency of $3 \mathrm{~Hz}$.

Fig 19 shows the ANFIS controller's settling time is less than Mamdani controller. Moreover, the output speed of the system being controlled with
ANFIS is much smoother than the one with Mamdani FLC which is oscillatory. In a real case a vibration might be observed on the motor shaft of the system being controlled with FLCs.

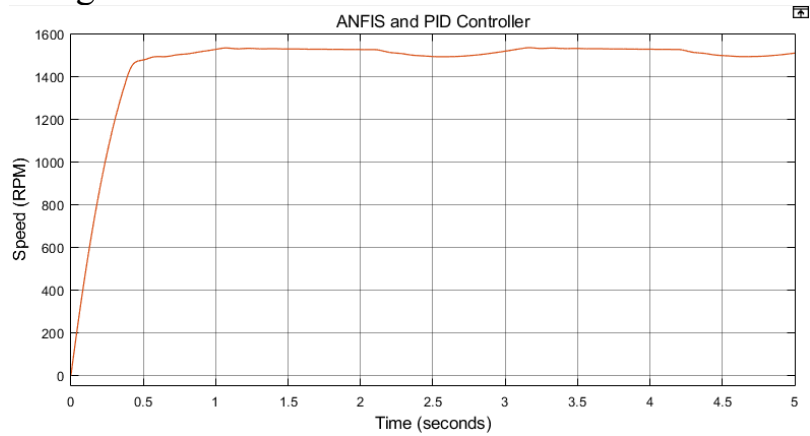

Fig 18. ANFIS assisting PID step response.

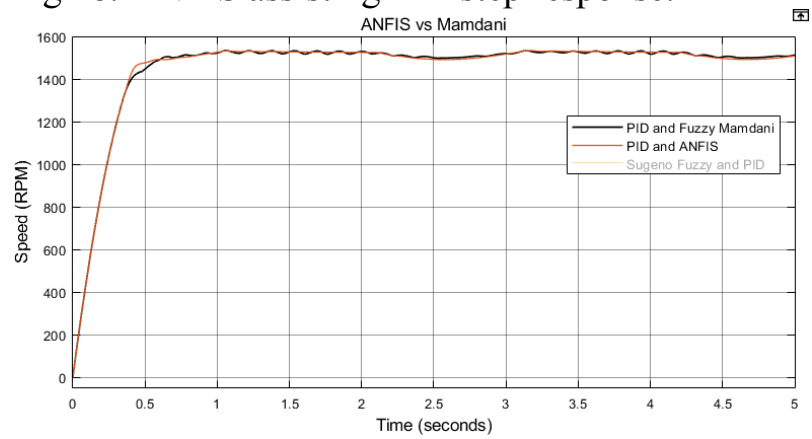

Fig 19. ANFIS vs Mamadani FLC step response.

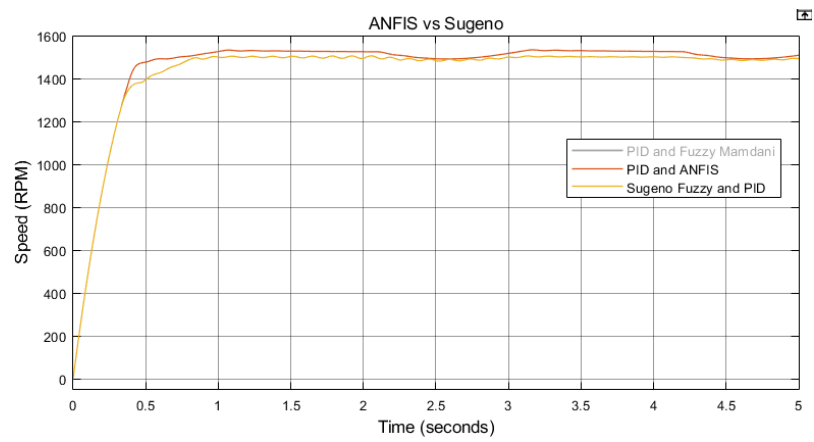

Fig 20. ANFIS vs Sugeno FLC step response.

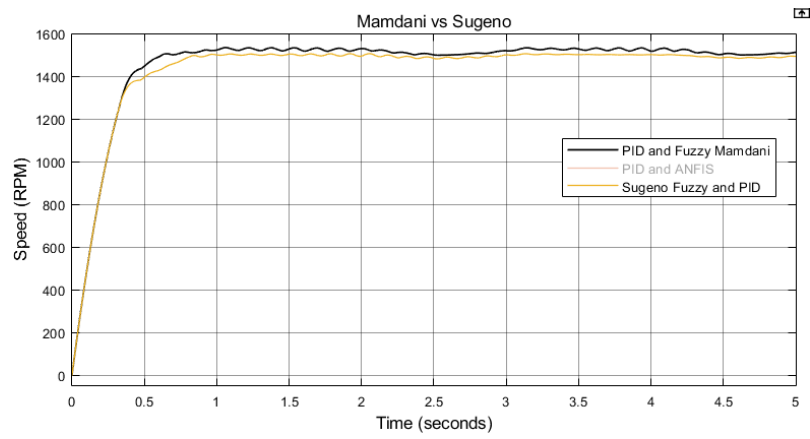

Fig 21. Mamdani vs Sugeno FLC. 
Fig 20 compares the ANFIS and Sugeno FLC step responses. ANFIS is faster than Sugeno in reaching the desire speed under 0.5 second and a lot smoother after settling.

When the shaft load is variable, the plant model is highly nonlinear. In this case, a linear controller (PID) is not able to control this plant. However, intelligent controllers can handle this nonlinear plant properly. In this case, ANFIS or FLC controllers assist a PID and keep the output speed near the desired point.

Fig 21 shows that Mamdani FLC provided a better response compared to Sugeno Zero-Order model, since the shaft speed reaches the desire speed faster.

To see how robust the ANFIS controller is, a set of tests are designed. First, a system with a changing load with a frequency of $3 \mathrm{~Hz}$ and the desire speed of 500 RPM is compared with the same system with constant load on shaft. The step response is represented in fig 22. This fig shows that the step response for under changing load is very close to the response for a fixed load

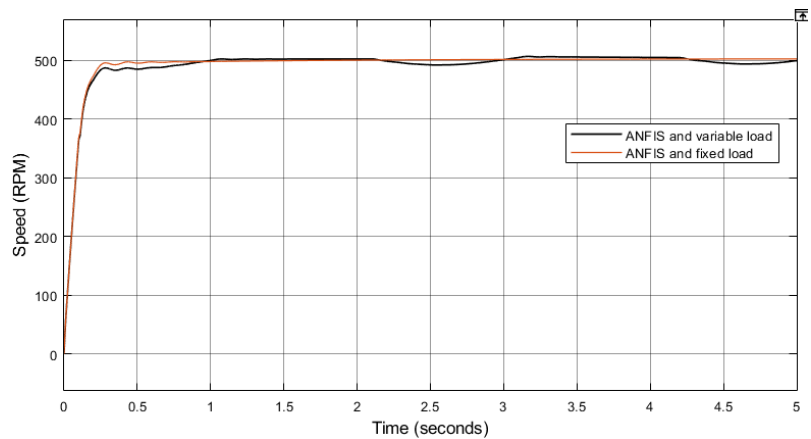

Fig 22. A constant and variable load are applied to the system controlled with ANFIS. The desire speed is 500 RPM.

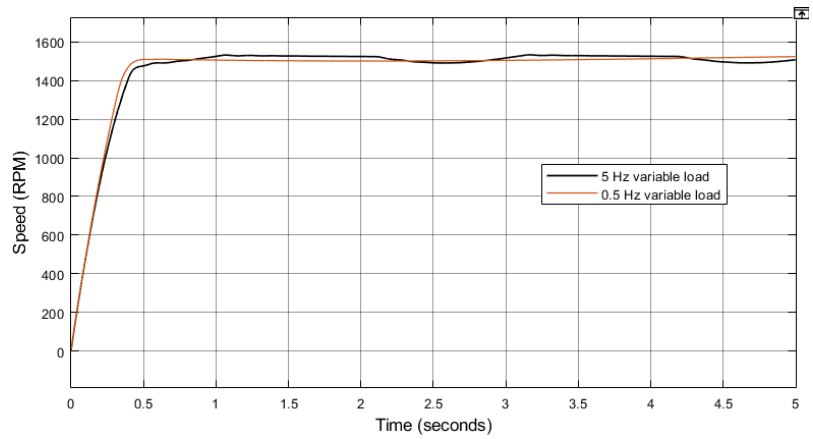

Fig 23. Different variable loads step response.

In the second test, the desire speed is 1500 RPM but the load changes with different frequencies. One with
$0.5 \mathrm{~Hz}$ and the other with $5 \mathrm{~Hz}$ are oscillating. The step response for these two models are illustrated in fig 23 . When the frequency is low enough, the step response is the same as the one for a fixed load. Compared to previous models, ANFIS provides the best performance for being optimized while training. Some relevant studies can be found in [10] and [11].

\section{Conclusions}

The application of intelligent controllers to a nonlinear plant which is very difficult to control with linear controllers is studied here. The BDCM shaft speed deviation was more than 15 percent of the desired speed with a linear controller regulation, while intelligent controllers, especially ANFIS, reduced it to less than two percent. ANFIS showed as the most powerful controller, however FLC controllers were also successfully applied to this plant. There are two characters that make ANFIS a better controller compared to others. First, load changes and desired speed changes can affect the speed regulation in most of the controllers. But, ANFIS showed very robust in both tests one and two. For ANFIS, when the speed increases or the load changes with different frequencies, the speed deviation never exceeds $2 \%$ of $D_{s}$. Second, FLC controllers have good regulation in some cases, but the output is still oscillatory. ANFIS showed a lot smoother and more reliable. Additionally, when the load was constant no overshoot was recorded for ANFIS (fig 22). ANFIS is robust in fixed loads and variable loads, different rates of load change, and different shaft speeds. The ANFIS performance is stable and reliable in different situations and it can be considered as a dynamic controller for a sensor-less BDCM plant.

Application of this study in automatic door systems can save a great deal of time and cost, since it reduces the number of services and increases the speed and simplicity of these services.

\section{References:}

[1] A. A. Sadiq, G.A. Bakare, E. C. Anene, and H. B. Mamman, "A Fuzzy-Based Speed Control of DC Motor Using Combined Armature Voltage and Field Current," $3^{\text {rd }}$ IFAC International Conference on Intelligent Control and Automation Science., 2013. 
[2] G. G. Rigatos, "Adaptive fuzzy control of DC motors using state and output feedback," Electric Power Systems Research 79 , p. 1579-1592, 2009.

[3] Alejandro Rodriguez-Molina, Miguel Gabriel Villarreal-Cervantes, and Mario Aldape-Perez, "An adaptive control study for a DC motor using meta-heuristic algorithms," IFAC PapersOnLine 50-1, p. 13114-13120, 2017.

[4] Victor Dutta, Terence O'Donnell, Subhramitra Borkakati, and Deepjyoti Bora, "PI-Fuzzy rule based controller for Analysis and performance evaluation of dc motor speed control," The 2nd IEEE Conference on Power Engineering and Renewable Energy, ICPERE , 2014.

[5] Muñoz-César J. J., Merchán-Cruz E. A., Hernández-Gómez L. H., Guerrero-Guadarrama E., Jiménez-Ledesma A., and Jaidar-Monter I., "Speed Control of a DC Brush Motor with Conventional PID and Fuzzy PI controllers," Electronics, Robotics and Automotive Mechanics Conference, 2008.

[6] Perez Claudia and Strefezza Miguel, "Speed Control of a DC Motor by Using Fuzzy Variable Structure Controller," Proceedings of the 27th Chinese Control Conference, 2008.

[7] Yasser Ali Almatheel and Ahmed Abdelrahman, "Speed Control of DC Motor Using Fuzzy Logic Controller," International Conference on Communication, Control, Computing and Electronics Engineering (ICCCCEE), 2017.

[8] Rasoul Rahmani, M.S. Mahmodian, Saad Mekhilef, and A. A. Shojaei, "Fuzzy Logic Controller Optimized by Particle Swarm Optimization for DC Motor Speed Control," IEEE Student Conference on Research and Development, 2012.

[9] Akhil v. Gite, Raksha M. Bodade, and Bhagyashri M. Raut, "ANFIS controller and its application," International Journal of Engineering Research \& Technology (IJERT), 2013.

[10] Wei Yang, Yi Chai, Jie Zheng, Jie Liu, Intelligent Diagnosis Technology of Wind Turbine Drive System based on Neural Network, WSEAS Transactions on Circuits and Systems, pp. 289-296, Volume 19, 2020
[11] Alena Vagaská, Peter Michal, Ivo Bukovský, Miroslav Gombár, Ján Kmec, The Application of Neural Networks to Control Technological Process, WSEAS Transactions on Circuits and Systems, pp. 147-153, Volume 18, 2019

\section{Sources of funding}

This paper research was supported by a grant from the Natural Sciences and Engineering Research Council (NSERC) of Canada.

\section{Creative Commons Attribution License 4.0 (Attribution 4.0 International, CC BY 4.0)}

This article is published under the terms of the Creative Commons Attribution License 4.0

https://creativecommons.org/licenses/by/4.0/deed.en_US 